\title{
PENGARUH MODEL PEMBELAJARAN KOOPERATIF TIPE JIGSAW II TERHADAP HASIL BELAJAR FOTOGRAFI \\ (Studi Kasus Kelas X Multimedia SMK N 2 Pulau Punjung)
}

\author{
Popi Radyuli ${ }^{1}$ ), Rini Sefriani ${ }^{2}$ ) \\ Fakultas Keguruan Ilmu Pendidikan, Universitas Putra Indonesia 'YPTK' Padang \\ Email: popiradyuli@upiyptk.ac.id \\ Fakultas Keguruan Ilmu Pendidikan, Universitas Putra Indonesia 'YPTK' Padang \\ Email: rinisefriani@upiyptk.ac.id
}

\begin{abstract}
Abstrak-Penelitian ini bertujuan untuk mengetahui ada tidaknya pengaruh model pembelajaran kooperatif tipe Jigsaw II terhadap hasil belajar Fotografi kelas X Multimedia. Penelitian ini dilaksanakan di SMK Negeri 2 Pulau Punjung semester genap tahun ajaran 2016/2017. Metode penelitian yang digunakan adalah kuasi eksperimen dan teknik pengambilan sampel menggunakan Random Sampling. Sampel dalam penelitian ini, siswa kelas X MM2 sebagai kelas eksperimen dan kelas X MM3 sebagai kelas kontrol dengan jumlah siswa kelas eksperimen 21 siswa dan jumlah siswa kelas kontrol 21 siswa. Kelas eksperimen diberi perlakuan berupa model pembelajaran kooperatif tipe Jigsaw II dan kelas kontrol diberi perlakuan model pembelajaran konvensional. Instrumen penelitian yang digunakan adalah tes pilihan ganda sebanyak 30 butir soal. Berdasarkan hasil penelitian, hasil pengujian pada taraf signifikansi $\alpha 0,05$ (pada taraf 5\%) didapatkan nilai $t_{\text {hitung }}=7,082$ dan $t_{\text {tabel }}=2,021$ sehingga diperoleh $t_{\text {hitung }}>t_{\text {tabel }}(7,082>2,021)$. Dengan demikian $\mathrm{H}_{0}$ ditolak dan $\mathrm{H}_{1}$ diterima, yang berarti bahwa terdapat pengaruh positif penerapan model pembelajaran kooperatif tipe Jigsaw II terhadap hasil belajar Fotografi kelas X Multimedia di SMK Negeri 2 Pulau Punjung tahun ajaran 2016/2017.
\end{abstract}

Kata kunci : Kooperatif Tipe Jigsaw II, Hasil Belajar

\section{PENDAHULUAN}

Undang Undang No. 20 Tahun 2003 tentang Tujuan Pendidikan Nasional Bab II Pasal 3 yang berbunyi:

$\begin{array}{lrr}\text { "Pendidikan Nasional bertujuan } \\ \text { mengembangkan } & \text { kemampuan dan }\end{array}$ membentuk watak serta peradaban bangsa yang bermartabat dalam rangka mencerdaskan bangsa, bertujuan untuk berkembangnya potensi peserta didik agar menjadi manusia yang beriman dan bertakwa kepada Tuhan Yang Maha Esa, berakhlak mulia, sehat, berilmu, cakap, kreatif, mandiri dan menjadi warga negara yang demokratis serta bertanggung jawab".

Menanggapi PP Nomor 32 Tahun 2013 pemerintah dalam dunia pendidikan melakukan upaya agar instansi pendidikan melakukan pengembangan dan perbaikan pendidikan terus dilakukan secara intensif menuju kepada kreativitas siswa dalam mencapai hasil belajar yang optimal. Walaupun usaha telah dilakukan seoptimal mungkin, namun ada saja permasalahan yang sering muncul, yaitu tidak semua siswa berprestasi seperti yang diharapkan meskipun pada mereka telah diberikan perlakuan yang sama dalam belajar. Rendahnya kemauan belajar siswa disebabkan oleh kelemahan siswa, tidak tersedianya sumber-sumber belajar bagi siswa dan tidak terlepas dari kemampuan guru mengajar siswa. Guru mempunyai peranan yang besar dalam meningkatkan kualitas siswa, sehingga guru harus menjadi seorang yang kreatif didalam kegiatan belajar mengajar. Cara belajar siswa yang kurang efektif, karena guru di tuntut aktif sedangkan siswa bersifat pasif. Cara belajar ini menyebabkan kreativitas siswa tidak terlihat.

Berdasarkan hasil wawancara penulis dengan beberapa siswa kelas $\mathrm{X}$ jurusan Multimedia serta wawancara dengan beberapa orang guru dan juga berdasarkan observasi lansung yang penulis lakukan di SMK N 2 Pulau Punjung didapat bahwasanya guru cenderung menggunakan metode pembelajaran konvensional (ceramah, tanya jawab, pemberian tugas). Kegiatan belajar mengajar terfokus pada 
guru, sehingga proses belajar mengajar tidak kualitas dan karakteristik tertentu yang efektif yang berakibat pada rendahnya hasil ditetapkan oleh peneliti untuk dipelajari dan belajar siswa. kemudian ditarik kesimpulannya (Sugiyono,

Nana Sudjana (2009:22) hasil belajar 2013:80). Populasi dalam penelitian ini didefenisikan sebagai kemampuan-kemampuan berjumlah 62 orang.

yang dimiliki siswa setelah ia menerima pengalaman belajarnya. Agar dapat mencapai probability sampling. Dimana pada teknik ini hasil pembelajaran yang maksimal, perlu dikaji memberikan kesempatan yang sama pada setiap model pembelajaran yang cocok, seperti model anggota populasi untuk dipilih menjadi anggota pembelajaran kooperatif untuk meningkatkan sampel (Sugiyono, 2013:82). Pada teknik hasil belajar siswa. Slavin (dalam Isjoni, 2011: probability sampling, sampel yang dipilih 15) menyatakan bahwa "pembelajaran kooperatif menggunakan teknik simple random adalah suatu model pembelajaran dimana siswa sampling.Teknik ini merupakan cara belajar dan bekerja sama dalam kelompok- pengambilan anggota sampel dari populasi yang kelompok kecil secara kolaboratif yang dilakukan secara acak tanpa memperhatikan anggotanya terdiri dari 4-6 orang dengan struktur strata (tingkatan) yang ada dalam populasi itu kelompok heterogen". Model pembelajaran (Sugiyono, 2013:82). Sampel yang terpilih dalam kooperatif yang ditawarkan model pembelajaran penelitian adalah siswa kelas X MM2 sebagai Jigsaw II, Lie (1993:73), model kooperatif kelas eksperimen dengan jumlah siswa 21 orang, Jigsaw merupakan model belajar kooperatif $\mathrm{X}$ MM3 sebagai kelas kontrol dengan jumlah dengan cara siswa belajar dalam kelompok kecil siswa 21 orang.

yang terdiri atas empat sampai enam orang secara heterogen, dan siswa bekerjasama, saling meli ketergantungan positif dan bertanggung jawab eksperimen dan kelas kontrol adalah sebagai secara mandiri. Langkah-langkah model berikut:

pembelajaran kooperatif tipe jigsaw II dapat disajikan dalam skema berikut:

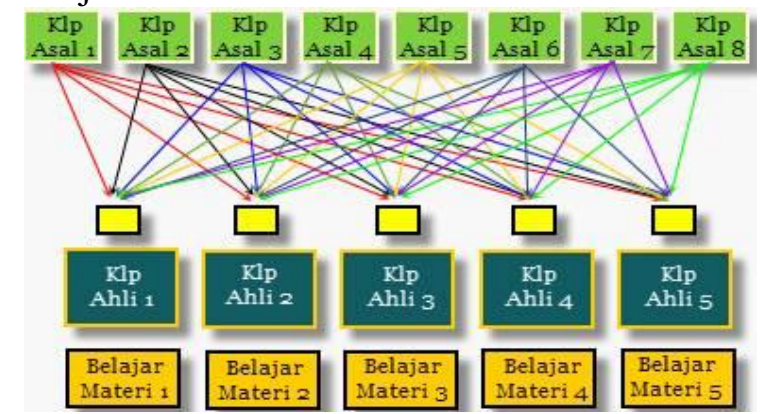

\section{Gambar 1. Skema Model Pembelajaran Jigsaw II}

\section{METODE PENELITIAN}

Jenis penelitian ini adalah penelitian eksperimen semu (Quasi Eksperimental Research). Sugiyono (2013:114), mengatakan bahwa: Quasi eksperimental research mempunyai kelompok kontrol, tetapi tidak dapat berfungsi sepenuhnya untuk mengontrol variabel-variabel luar yang mempengaruhi pelaksanaan eksperimen. Penelitian dilaksanakan pada siswa kelas X Multimedia pada mata pelajaran Fotografi Di SMKN 2 Pulau Punjung Semester Genap tahun ajaran 2016/2017.

Populasi adalah wilayah generalisasi yang terdiri atas objek/subjek yang mempunyai

\section{HASIL PENELITIAN DAN PEMBAHASAN}

Setelah dilakukan penelitian dan pengolahan data untuk masing-masing kelas, dapat diperlihatkan pada tabel berikut:

1. Uji Normalitas digunakan untuk menguji data setiap variabel yang akan dianalis berdistribusi normal. Pada penelitian ini teknik yang digunakan adalah uji Liliefors.

2. Uji homogenitas varian diperlukan untuk membandingkan dua kelompok atau lebih. Dalam penelitian ini uji homogenitas meggunakan uji $\mathrm{F}$.

3. Uji Hipotesis, pengujian hipotesis tentang kesamaan dua rata-rata dilakukan jika data terdistribusi normal dan kedua kelompok data homogen, maka dalam pengujian hipotesis statistik yang digunakan adalah uji t.

\section{perilhatkan pada tabel berikut:}


Tabel 1.Nilai Statistik Pemusatan Data Kelas Eksperimen dan Kelas Kontrol

\begin{tabular}{|c|l|c|c|}
\hline No & \multicolumn{1}{|c|}{ Statistik } & $\begin{array}{c}\text { Kelas } \\
\text { Eksperimen }\end{array}$ & Kelas Kontrol \\
\hline 1 & N & 21 & 21 \\
\hline 2 & Jumlah Nilai & 1840 & 1581 \\
\hline 3 & Mean (rata-rata) & 87,62 & 75,29 \\
\hline 4 & Median & 88 & 79 \\
\hline 5 & Modus & 89 & 76 \\
\hline 6 & Nilai Maksimum & 97 & 83 \\
\hline 7 & Nilai Minimum & 73 & 67 \\
\hline 8 & Range & 24 & 16 \\
\hline 9 & Interval & 5 & 5 \\
\hline 10 & Panjang Kelas Interval & 4 & 3 \\
\hline 11 & Varians & 38,24 & 25,41 \\
\hline 12 & Standar Deviasi & 6,180 & 5 \\
\hline
\end{tabular}

Hasil belajar kelas eksperimen dari 21 responden dan dimana dari data yang dikumpulkan menunjukkan bahwa nilai maksimum yang diperoleh 97 dan Minimum 73, berada pada interval (k) 5 dan panjang kelas interval 4. Hasil analisis data menunjukkan bahwa rata-rata hitung (M) untuk kelas eksperimen adalah 87,62, untuk Median (Me) adalah 88 untuk Modus (Mode) adalah 89, dimana varians untuk kelas eksperimen adalah 38,24 dan standar Deviasi (Sd) kelas eksperimen sebesar 6,180.

Hasil belajar kelas kontrol dari 21 responden dimana dari data yang dikumpulkan menunjukkan bahwa nilai maksimum yang diperoleh 83 dan Minimum 67, berada pada interval (k) 5 dan panjang kelas interval 3. Hasil analisis data menunjukkan bahwa rata-rata hitung (M) untuk kelas kontrol adalah 75,29, untuk Median (Me) adalah 79, untuk modus (Mode) adalah 77, dimana varians kelas kontrol adalah 25,41, Standar Deviasi (Sd) kelas kontrol sebesar 5.

Uji normalitas dilakukan secara parametrik dengan menggunakan penafsiran ratarata dan simpangan baku. Pada analisis uji normalitas ini, peneliti menggunakan uji normalitas yang dikenal dengan nama uji Liliefors. Berdasarkan uji normalitas kelas eksperimen dan kelas kontrol diperoleh harga Lo dan Lt pada taraf nyata 0,05 untuk $n>21$ dan 21 pada tabel 2. Berikut ini hasil perhitungan uji normalitas pada kedua sampel:

Tabel 2. Hasil Perhitungan Pengujian Liliefors Kelompo Eksperimen dan Kelompok Kontrol

\begin{tabular}{|c|c|c|c|c|c|}
\hline Kelas & $\mathrm{N}$ & A & $\begin{array}{c}\mathrm{L}_{\text {Lhitupg }} \\
\left(\mathrm{L}_{0}\right)\end{array}$ & $\frac{\mathrm{L}_{\text {tatabel }}}{\left(\mathrm{L}_{t}\right)}$ & Kesimpulan \\
\hline Eksperimen & 21 & 0,05 & $-0,0336$ & 0,187 & $\mathrm{~L}_{0}<\mathrm{L}_{\mathrm{t}}$ \\
\hline Kontrol & 21 & 0,05 & $-0,0175$ & 0,187 & Distribusi normal \\
\hline
\end{tabular}

Berdasarkan tabel 2, perhitungan uji Liliefors terlihat kelas eksperimen $\mathrm{L}_{\text {hitung }}-0,0336$ lebih kecil dari $\mathrm{L}_{\text {tabel }} 0,187$ untuk $\alpha 0,05$ dan kelas kontrol $\mathrm{L}_{\text {hitung }}-0,0175$ lebih kecil dari $\mathrm{L}_{\text {tabel }}$
0,187 untuk $\alpha 0,05$. Ini terlihat bahwa data kelas kontrol dan kelas eksperimen berasal dari data yang berdistribusi normal.

Persyaratan analisis yang berikutnya adalah uji homogenitas varians. Uji homogenitas varians dimaksudkan untuk mengetahui apakah sampel penelitian berasal dari populasi yang bersifat homogen atau tidak. Uji homogenitas pada dua kelompok perlakuan dilakukan dengan menggunakan statistik $\mathrm{F}$ untuk menghitung $\mathrm{F}$ ratio dengan cara membagi varians terbesar dengan varians terkecil. Kriteria yang digunakan adalah kelompok homogen bila $\mathrm{F}_{\text {hitung }}$ lebih kecil dari pada $\mathrm{F}_{\text {tabel }}$. Ringkasan hasil perhitungan uji homogenitas disajikan pada tabel berikut:

Tabel 3.Uji Homogenitas Hasil Belajar Kelas Eksperimen dan Kelas Kontrol

\begin{tabular}{|c|c|c|c|c|c|c|c|}
\hline No & Kelas. & $\mathrm{N}$ & $\mathrm{dk}$ & $\alpha$ & $\mathrm{F}_{\mathrm{h}}$ & $F_{t}$ & Kesimpulan \\
\hline 1 & Eksperimen & 21 & 20 & \multirow{2}{*}{0.05} & \multirow{2}{*}{1,504} & \multirow{2}{*}{2,12} & $\mathrm{~F}_{\text {hitumg }}<\mathrm{F}_{\text {tabel }}$ \\
\hline 2 & Kontrol & 21 & 20 & & & & $\begin{array}{l}\text { vanans } \\
\text { Homogen }\end{array}$ \\
\hline
\end{tabular}

Hasil perhitungan menunjukkan bahwa dalam kelompok perlakuan diketahui varians $\left(\mathrm{S}_{1}^{2}\right)$ terbesar adalah 38,24 dan varians terkecil $\left(S_{2}^{2}\right)$ adalah 25,41. Dengan membagikan kedua angka tersebut diperoleh indeks homogenitas varians antara dua kelompok yang diuji dan nilai dk pembilang 20 dan dk penyebut 20 . Nilai $F_{\text {hitung }}$ sebesar 1,504 dan $F_{\text {tabel }} 2,12$. Dengan demikian $F_{\text {hitung }}<F_{\text {tabel}}$, yang berarti dapat dinyatakan bahwa dua kelompok yang diuji bersifat homogen.

Berdasarkan analisis data berupa uji normalitas dan homogenitas diperoleh kesimpulan bahwa sampel berdistribusi normal dan homogen. Maka langkah berikutnya dapat dilanjutkan pada pengujian hipotesis dengan menggunakan uji t. Berikut ini digambarkan pengolahan data dengan $t_{\text {test }}$ pada tabel 4 .

Tabel 4. Uji Hipotesis Hasil Belajar Kelas Eksperimen dan Kontrol

\begin{tabular}{|c|c|c|c|c|c|c|c|c|}
\hline $\mathrm{N}_{0}$ & Kelas & $\mathrm{N}$ & $\mathrm{X}$ & S & $\mathrm{dk}$ & $t_{h}$ & $\mathrm{t}$ & Kesimpulan \\
\hline 1 & Eksperimen & 21 & 87,61 & 38,24 & \multirow[b]{2}{*}{40} & \multirow[b]{2}{*}{7,082} & \multirow[b]{2}{*}{2,021} & \multirow{2}{*}{$\begin{array}{l}t_{\text {hituge }} \text { tragel } \\
\mathrm{H}_{\mathrm{a}} \text { Diterima }\end{array}$} \\
\hline 2 & Kontrol & 21 & 75,28 & 25,41 & & & & \\
\hline
\end{tabular}

Hasil pengujian pada taraf signifikansi $\alpha$ 0.05 (taraf kepercayaan 95\%) diperoleh $\mathrm{t}_{\text {hitung }}=$ 7,082 dan $t_{\text {tabel }}=2,021$ sehingga diperoleh $t_{\text {hitung }}>t_{\text {tabel }}(7,082>2,021)$. Karena $t_{\text {hitung }}>t_{\text {tabel }}$ dengan menggunakan uji dua pihak (two tail test) maka hipotesis diterima, dengan demikian $\mathrm{H}_{0}$ ditolakdan $\mathrm{H}_{1}$ diterima, yang berarti bahwa terdapat perbedaan yang signifikan antara hasil belajar siswa yang diberi model pembelajaran 
Jigsaw II dengan hasil belajar siswa yang memperhatikan pelajaran dengan baik, bahkan menggunakan model pembelajaran konvensional ada siswa yang tidak memperhatikan pelajaran pada mata pelajaran Fotografi siswa kelas sama sekali. Hal ini disebabkan oleh proses Multimedia SMKN 2 Pulau Punjung Semester belajar mengajar yang bersifat satu arah, Genap Tahun Ajaran 2016/2017. sehingga tidak terjalin komunikasi yang baik

\section{PEMBAHASAN}

Penelitian yang dilakukan keberhasilannya dapat dilihat dari hasil uji hipotesis yang telah dilakukan menggunakan rumus uji t, diperoleh nilai $t_{\text {hitung }}>t_{\text {tabel }}$. Sehingga dapat dikatakan hipotesis yang diajukan telah diterima. Hasil belajar siswa yang menggunakan metode pembelajaran kooperatif tipe Jigsaw II lebih tinggi dibandingkan siswa yang menggunakan metode konvensional demonstrasi pada mata pelajaran Fotografi kelas $\mathrm{X}$ Multimedia di SMKN 2 Pulau Punjung semester genap tahun ajaran 2016/2017. Hal tersebut dapat dilihat dari nilai rata-rata kelas eksperimen dan kelas kontrol. Dimana kelas eksperimen yang diterapkan metode pembelajaran kooperatif tipe Jigsaw II memperoleh rata-rata 87,62 Sedangkan kelas kontrol yang diterapkan metode konvensional demonstrasi memperoleh rata-rata 75,29. Maka dapat dilihat terdapat perbedaan hasil belajar yang cukup berarti antara kelas eksperimen dan kontrol.

Perbedaan hasil belajar pada kelas eksperimen dan kelas kontrol disebabkan siswa yang berada pada kelas eksperimen memiliki motivasi belajar yang tinggi, hal ini terlihat dari keaktifan siswa dalam mengikuti proses belajar mengajar. Selain itu, siswa juga terlihat tenang dan nyaman berada di dalam kelas. Pada metode kooperatif tipe Jigsaw II ini, siswa diminta untuk membaca topik atau materi yang akan dijadikan pembahasan dalam pembelajaran. Setelah itu siswa dibagi dalam empat kelompok (kelompok asal) dan guru mulai membagikan materi untuk masing-masing siswa, selanjutnya guru mengarahkan siswa untuk bergabung kedalam kelompok yang mendapatkan materi yang sama (kelompok ahli) agar mendiskusikan materi yang telah diberikan. Setelah kelompok ahli berdiskusi, maka kelompok ahli tersebut diminta untuk kembali kedalam kelompok asal untuk menjelaskan mengenai materi yang telah mereka kuasai. Sedangkan pada kelas kontrol yang menggunakan metode konvensional, siswa cenderung kurang bersemangat dan tidak fokus dalam mengikuti proses belajar mengajar di kelas. Dimana banyak siswa yang tidak antara guru dan siswa. Guru merupakan pusat pembelajaran, sedangkan siswa sebagai penerima pasif. Setelah diterapkan metode pembelajaran kooperatif tipe Jigsaw II pada siswa kelas X Multimedia di SMK Negeri 2 Pulau Punjung semester genap tahun ajaran 2016/2017, diperoleh nilai rata-rata siswa yang di atas standar ketuntasan minimal yaitu 75. Bukan hanya itu, hubungan guru dan siswa pun terjalin lebih baik dari sebelumnya.

Penggunaan metode pembelajaran kooperatif tipe Jigsaw II dapat meningkatkan motivasi belajar siswa, sehingga hasil belajarnya pun meningkat. Dimana model pembelajaran kooperatif tipe Jigsaw II adalah model pembelajaran yang terdiri dari kelompok asal dan kelompok ahli. Salah satu landasan teoritis tentang model pembelajran Jigsaw II menurut Slavin (2015:236) pembelajaran kooperatif tipe Jigsaw pertama kali dikembangkan oleh Elliot Aronson dan rekan-rekannya (1978). Metode orisinilnya, secara singkat digambarkan dalam bagian ini, membutuhkan pengembangan yang ekstensif dari materi-materi khusus. Bentuk adaptasi Jigsaw yang lebih praktis dan mudah. Para siswa tersebut diberikan tugas untuk membaca beberapa bab atau unit, dan diberkan "lembar ahli" yang terdiri atas topik-topik yang berbeda yang harus menjadi fokus perhatian masing-masing anggota tim saat mereka membaca. Setelah semua anak selesai membaca, siswa-siswa dari tim yang berbeda yang mempunyai fokus topik yang sama bertemu dalam "kelompok ahli" yang terdiri atas topiktopik yang berbeda yang harus menjadi fokus perhatian masing-masing anggota tim saat mereka membaca. Setelah semua anak selesai membaca, siswa-siswa dari tim yang berbeda yang mempunyai fokus topik yang sama bertemu dalam "kelompok ahli" untuk mendiskusikan topik mereka sekitar tiga puluh menit.

Persamaan penelitian terdahulu dengan yang saya teliti terletak pada model pembelajaran yang diterapkan sama. Pada pengujian normalitas kelas eksperimen $\mathrm{L}_{\text {hitung }}$ lebih kecil dari $\mathrm{L}_{\text {tabel}}$, dimana $L_{\text {hitung }}-0,0336<\mathrm{L}_{\text {tabel }} 0,187$ untuk $\alpha 0,05$, dan kelas kontrol $\mathrm{L}_{\text {hitung }}-0,0175<\mathrm{L}_{\text {tabel }} 0,187$ untuk $\alpha 0,05$, maka data kelas kontrol dan kelas eksperimen berdistribusi normal. Selanjutnya, 
pada pengujian homogenitas data dari kedua kelompok diperoleh hasil $\mathrm{F}_{\text {hitung }}<\mathrm{F}_{\text {tabel, }}$, yaitu 1,504< 2,012 maka kedua kelompok memiliki varians yang homogen untuk $\alpha 0,05$. Sedangkan, pada pengujian hipotesis dengan menggunakan ttest diperoleh hasil $t_{\text {hitung }}>\mathrm{t}_{\text {tabel }}$ untuk $\alpha 0,05$ yaitu $7,082>2,021$. Maka dapat disimpulkan bahwa $\mathrm{H}_{1}$ diterima dan $\mathrm{H}_{0}$ ditolak. Berdasarkan uraian tersebut dapat
disimpulkan bahwa penerapan model pembelajaran Jigsaw II terhadap hasil belajar fotografi kelas X MM SMKN 2 Pulau Punjung dapat berpengaruh terhadap hasil belajar siswa dibandingkan dengan pembelajaran yang menggunakan model pembelajaran konvensional.

\section{KESIMPULAN}

Berdasarkan hasil penelitian, dimana pada kelas eksperimen yang diberi pengajaran dengan menggunakan model pembelajaran Jigsaw II maka diperoleh rata-ratanya adalah 87,61 sedangkan siswa yang diberi pengajaran menggunakan model konvensional rata-ratanya adalah 75,28. Pada pengujian normalitas kelas eksperimen $\mathrm{L}_{\text {hitung }}-0,0336$ lebih kecil dari $\mathrm{L}_{\text {tabel }}$ 0,187 untuk $\alpha 0,05$, dan kelas kontrol $\mathrm{L}_{\text {hitung }}$ 0,0175 lebih kecil dari $\mathrm{L}_{\text {tabel }} 0,187$ untuk $\alpha 0,05$, maka data kelas kontrol dan kelas eksperimen berdistribusi normal.

Pengujian homogenitas data dari kedua kelompok diperoleh hasil $\mathrm{F}_{\text {hitung }}<\mathrm{F}_{\text {tabel}}$, yaitu $1,504<2,12$ maka kedua kelompok memiliki varians yang homogen untuk $\alpha 0,05$. Sedangkan, pada pengujian hipotesis dengan menggunakan ttest diperoleh hasil $t_{\text {hitung }}>t_{\text {tabel }}$ untuk $\alpha 0,05$ yaitu $7,082>2,021$. Dapat diambil kesimpulan bahwa terdapat pengaruh yang positif dan signifikan pada penerapan model pembelajaran Jigsaw II terhadap hasil belajar Siswa Pada Mata Pelajaran Fotografi kelas X Multimedia Di SMKN 2 Pulau Punjung Semester Genap Tahun Ajaran 2016/2017.

Hal ini membuktikan bahwa model pembelajaran Jigsaw II berpengaruh terhadap hasil belajar Fotografi secara signifikan dibandingkan dengan menggunakan model pembelajaran konvensional.

\section{DAFTAR RUJUKAN}

Anas, Sudijono. 2011. Pengantar Evaluasi Pendidikan. Jakarta :Rajawali Pers.

Arend.1997.Model-Model Pembelajaran Terpadu. Bandung: Erlangga.

Departemen Pendidikan Nasional, 2003. Undang-Undang Nomor 20 Tahun 2003,

Tentang Sistem Pendidikan Nasional. Jakarta: Depdiknas.

Lie. 1993. Metode Pembelajaran.Jakarta: RinekaCipta.

Nana, Sudjana.2009. Penilaian Hasil Proses Belajar Mengajar. Bandung: Remaja osdakarya.

Peraturan Pemerintah Republik Indonesia Nomor 32 Tahun 2013 tentang Standar Nasional Pendidikan. Jakarta: Depdiknas.

Ratna, Wilis. 2006. Teori-Teori Belajar dan Pembelajaran. Bandung: Erlangga.

Slavin, Robert E. 2015. Cooperative Learning. Bandung : Nusa Media

Sugiyono. 2010. Statistik untuk Penelitian. Bandung: AlFABETA.2013.

Syaiful, Sagala. 2013. Konsep dan Makna Pembelajaran. Bandung: Alfabeta. 
Volume 3 Nomor 2, Halaman 1-77, Juli-Desember 2018

RISTEKDIK / Jurnal Bimbingan dan Konseling

P-ISSN: 2527-4244, E-ISSN : 2541-206X 